\title{
1924-2018 Ortaokul Matematik Öğretim Programlarının Geometrik Düşünme Alışkanlıkları Bakımından İncelenmesi*
}

\author{
Examining Middle School Mathematics Curriculum from \\ 1924 to 2018 with Respect to Geometric Habits of Mind
}

\author{
Emine ERASLAN YALÇIN**, Meriç ÖZGELDİ***
}

\begin{abstract}
Öz: Bu çalışmanın amacı, Cumhuriyetin ilanından günümüze (1924-2018) ortaokul matematik öğretim programları geometri ve ölçme öğrenme alanındaki kazanımları, geometrik düşünme alışkanlıkları bakımından incelemektir. Araştırma, Cumhuriyet döneminde uygulanan 1924, 1930, 1938, 1949, 1951, 1962, 1970, 1988, 1995, 1997, 2002, 2005, 2009, 2013, 2015 ve 2018 ortaokul matematik öğretim programlarını kapsamaktadır. Bu on altı ögretim programında geometri ve ölçme öğrenme alanındaki kazanımlar geometrik düşünme alışkanlıkları bakımından incelenmiştir. $\mathrm{Bu}$ incelemede ortaokul matematik öğretim programları değerlendirilirken Driscoll, DiMatteo, Nikula ve Egan'ın (2007) önerdiği ilişki kurarak muhakeme etme, geometrik fikirlerin genelleştirilmesi, değişmeyenlerin incelenmesi ile keşfetme ve yansıma dengesi kurma şeklindeki alışkanlık sınıflandırması temel alınmıştır. Bu araştırmanın sonucunda 2005 yılına kadar uygulanan ortaokul matematik öğretim programlarının geometri ve ölçme öğrenme alanına ilişkin kazanımlarının ağırlıklı olarak ilişki kurarak muhakeme etme alışkanlığını kazandırmaya yönelik olduğu, 2005 ve sonrası uygulanan ortaokul matematik öğretim programlarının geometri ve ölçme öğrenme alanı kazanımlarının ise tüm geometrik düşünme alışkanlıklarını kazandırmaya dönük olduğu tespit edilmiştir.
\end{abstract}

Anahtar Kelimeler: Geometrik düşünme, geometrik düşünme alışkanlıkları, ortaokul matematik öğretim programları

\begin{abstract}
The purpose of the study was to examine the intended learning outcomes in geometry and measurement learning area in the middle school mathematics curriculum which were applied from 1924 to 2018 with respect to geometric habits of mind. This research covered the 1924, 1930, 1938, 1949, 1951, 1962, 1970, 1988, 1995, 1997, 2002, 2005, 2009, 2013, 2015 and 2018 middle school mathematics curriculum implemented during the Republican period. The intended learning outcomes in these sixteen mathematics curriculums were examined with respect to geometric habits of mind. In particular, they were examined based on the framework proposed by Driscoll, DiMatteo, Nikula and Egan (2007) for the geometric habits of minds (i.e. reasoning with relationships, generalizing geometric ideas, investigating invariants and balancing exploration and reflection). The findings of this study showed that the learning outcomes in the middle school mathematics curriculums applied until 2005 were predominantly aimed at acquiring the habit of reasoning with relationships, whereas the mathematics curriculums applied in 2005 and after were aimed at gaining all types of geometric habits of minds.
\end{abstract}

Keywords: Geometric thinking, geometric habits of mind, middle school mathematics curriculum

\section{Giriş}

Matematiğin bireylere formal olarak öğretildiği ilk yer olan okullarda değişim kendini göstermek zorundadır (Trautwein, Koller, Schmitz ve Baumert, 2002). Matematik dersi öğretim programları da gerek bilimsel, sosyal veya toplumsal yenilikler, gerekse öğrenme öğretme teori ve yaklaşımlarındaki yenilik ve gelişmeler doğrultusunda değişime ihtiyaç duymaktadır. Bu bağlamda, öğrencilerin ihtiyaçlarına cevap verebilen, onların düşünme becerilerini geliştirerek

\footnotetext{
* Bu çalışma birinci yazarın yüksek lisans tez çalışmasının bir kısmını kapsamaktadır.

**öğretmen, Değirmençay Ortaokulu, Mersin-Türkiye, ORCID: 0000-0003-3573-2941, e-posta: eeraslanyalcin@gmail.com

*** Dr.Öğr.Üyesi, Mersin Üniversitesi, Eğitim Fakültesi, Mersin-Türkiye, ORCID: 0000-0002-4623-9397, e-posta: mericozgeldi@mersin.edu.tr
} 
tüm kapasitelerini kullanabilmelerine imkân sağlayan öğretim programlarının hazırlanması oldukça önemlidir (Ersoy ve Başer, 2013).

Program değerlendirme çalışmaları öğretim programlarının yenilenmesi, gelişmesi, sürekliliğinin sağlanması ve uygulanmasını desteklemek amacıyla yapılmaktadır (Uşun, 2016). Çoğunlukla, programların değerlendirilmesine yönelik yapılan çalışmalar programların uygulanmaya başladığ 1 yıl yoğunluk kazanmış, zamanla aşamalı olarak azalma eğilimi göstermiştir (Kablan, 2011). Cumhuriyetten günümüze öğretim programlarının incelendiği çalışmalar ortaokul düzeyinde Fen, Türkçe ve Sosyal Bilgiler öğretim programlarının karşılaştırmalı çalışmaları olmuştur (Balcı, Coşkun ve Taner, 2012; Girgin, 2011; Gökdemir, 2013; Keskin, 2012; Yakar, 2013). Matematik öğretim programları karşılaştırma çalışmaları incelendiğinde genellikle 2005 yılından sonraki programların karşılaştırıldığı görülmüş; 2005 'ten önceki programlar ise nadiren incelenmiştir (Danışman ve Karadağ, 2015; Delil ve Güleş, 2007; Kablan, Baran ve Hazer, 2013; Şen, 2017). Örneğin, Danışman ve Karadağ'ın (2015) beşinci sınıf seviyesinde, 2005 ilköğretim ve 2013 ortaokul matematik öğretim programları öğrenme alanları ve kazanımlarının karşılaştırıldığı çalışmasında, 2005 öğretim programının önemli ölçüde sadeleştiği, 2013 programına eklenen bazı öğrenme alanları ve kazanımları ile matematiğe ayrılan ders saati sayısının arttığ diğerleri (2013) ise 2005 taslak programından sonra yayınlanan ilköğretim matematik programını üst bilişsel seviyeye işaret eden ifadelere (örneğin, oluşturur, inşa eder) göre incelemiş; özellikle etkinliklerin üst bilişsel seviyeyi gerektirecek beceriler içermediğini, bu nedenle programın üst düzey becerileri kazandıracak şekilde yeniden ele alınmasının faydalı olacağını belirtmiştir. Benzer biçimde, Şen (2017) 2009-2013-2017 yıllarında yayınlanan matematik dersi öğretim (5-8. sınıf) programlarını vizyon, yaklaşım, felsefe, öğrenme alanları, kazanımlar, beceriler ve programın uygulama basamakları açılarından karşılaştırmalı olarak incelemiştir. Bununla birlikte, 2013 ve 2017 ortaokul matematik öğretim programların felsefesinin net bir şekilde belirtilmediği, kazanım sayılarının değişen programlarla birlikte azaldığı, her üç programın da öğrencilere kazandırmaya çalıştığı becerilerin ortak olduğu belirtilmiştir. Sonuç olarak, alan yazında ilgili çalışmalarda genellikle ortaokul matematik programları programların felsefesi, kazandırmaya çalıştığı kazanımları ve becerileri çerçevesinde incelenmiş ve karşılaştırmalı olarak ele alınmıştır.

Genelde matematik, özelde ise geometri öğretim programlarının asıl amacı, karşılaştığ problemlerin üstesinden gelebilen bireyler yetiştirmektir. Bu bireylerin yetiştirilebilmesi için de matematik ve geometrik düşünme alışkanlıkları doğrultusunda öğretim programlarının şekillenmesi gerekir (Cuoco, Goldenberg ve Mark, 2010; Goldenberg, 1996; Mark, Cuoco, Goldenberg ve Sword, 2010). Matematiğin nasıl uygulanacağını ve öğrenileceğini destekleyen alışkanlıklar Goldenberg, Cuoco ve Mark (1998) tarafindan matematiksel güç ile eşdeğer görülmüş ve matematiksel güç en iyi düşünme alışkanlıklarının bütünü olarak tanımlanmıştır. Matematiksel gücü tanımlayan düşünme alışkanlıkları, matematiğin bazı özel alanlarında daha da ön plana çıkmış, örneğin cebir ve geometride özellikle son yıllarda önem kazanan çalışma alanları olarak değerlendirilmiştir. Özellikle geometri öğretimi alanında yapılan çalışmalarda, geometrik düşünme alışkanlıklarının matematik programlarının düzenleyici bir öğesi olduğu ve bu alışkanlıkların öğrencilere öğretim programları ile kazandırılabileceği belirtilmektedir (Cuoco ve diğerleri, 2010). Bu nedenle, karşılaştığ1 problemlerin üstesinden gelebilen bireyler yetiştirebilmek için ögretim programlarının, matematik ve geometrik düşünme alışkanlıklarını kapsayacak şekilde kazanımlar içermesi ve bu şekilde hazırlanması önem kazanmaktadır (Cuoco ve diğerleri, 2010; Goldenberg, 1996; Mark ve diğerleri, 2010). Bu kapsamda, geometrik düşünme alışkanlıklarının teorik çerçevesi ve ilgili çalışmalar bir sonraki başlıkta ayrıntılı olarak ele alınmıştır.

\section{Geometrik düșünme alışkanlıkları}

Bir sonuca ulaşmak için var olan kavramların ve ilkelerin ilişkilendirildiği zihinsel süreçler, düşünme olarak adlandırılır (Leikin, 2007). Matematiksel düşünme ise uygun sonuca gitmek için matematiksel teknik, kavram ve yöntemleri problem çözme sürecinde dolaylı ya da 
doğrudan kullanmaktır (Henderson ve diğerleri, 2004). Değişik alanlarda kullanılan matematiksel tekniklerin doğasına bağlı olarak matematiksel düşünme, cebirsel düşünme, geometrik düşünme ve olasılıklı düşünme gibi farklı biçimlerde ortaya çıkmaktadır (Dindyal, 2003). Geometrik düşünme ise bireylerin geometrik şekiller, kavramlar ve prensipler arasında ilişkiler kurarak geometri problemlerini çözebilmelerine olanak sağlayan bir düşünme şeklidir (Van de Walle, Karp ve Bay-Williams, 2014). Her tür düşünme süreci bir takım zihinsel alışkanlıklarla geliştirilir. Zihinsel alışkanlıklar ise bir problem karşısında kişinin muhakeme, yaratıcılık, ustalık gibi entelektüel davranma yeteneğine sahip olması durumudur. Zihinsel alışkanlıkların işleyişi entelektüel davranışların etkili modellerini seçme eğilimi ve yeteneği şeklinde tanımlanabilir (Leikin, 2007). Başka bir ifadeyle, kişi bir problem durumunun çözümünde etkin bir stratejiyi seçmek ve bu stratejiyi uygulamak için kişisel bir yönelim gösterir. Geometrik düşünme sürecinin işler hale gelmesi için de kazanılması gereken geometrik düşünme alışkanlıkları vardır.

Geometrik düşünme alışkanlıkları, matematiksel düşünme alışkanlıklarının bir alt basamağını oluşturur. Bu nedenle geometrik düşünme alışkanlıkları, düşünme alışkanlıkları ve matematiksel düşünme alışkanlıkları ile yakından ilişkilidir. Literatürde araştırmacılar tarafından farklı düşünme alışkanlıkları tanımlanmıştır (Costa ve Kallick, 2000; Cuoco ve diğerleri, 1996; Hew ve Cheung, 2010; Leikin, 2007; Marzano, Pickering ve McTighe, 1993). Marzano ve diğerleri (1993) düşünme alışkanlıklarını, genel olarak bireyin herhangi bir problem durumuyla karşılaştığında sahip olduğu bilginin farkına varması, bu bilgileri karşılaşılan problem durumunda kullanabilmesi ve bilgileri yeni durumlara uyarlayabilmesi gibi bilişsel boyutlar olarak ifade etmiştir. Duyuşsal boyut olarak ise bireyin kendine olan güven duygusu ve bu güven duygusu yardımıyla problemlere karşı farklı bakış açısı geliştirebilmesi olarak tanımlamıştır. Benzer biçimde, Costa ve Kallick (2008) düşünme alışkanlıklarını problemlerin cevabının doğrudan görülemediği durumlarda zeki bireylerin çözüme yönelik yaklaşımları olarak ifade etmiş ve aslında zeki insanların sadece bilgiyle ilgilenmediğini aynı zamanda bilginin nasıl oluştuğuna odaklandığını da belirtmiștir. Cuoco ve diğerleri (2010) ise düşünme alışkanlıklarını genel düşünme alışkanlıkları ve matematiğe özgü düşünme alışkanlıkları olmak üzere iki başlıkta incelemiştir. Genel düşünme alışkanlıkları örüntüyü algılama, araştırma, tanımlama, düşünme, keşfetme, görselleştirme, varsayımda bulunma ve tahmin etme gibi temel özelliklerle açıklanmıştır. Matematiğe özgü düşünme alışkanlıklarını ise sıra dışı durumlarda düşünce deneyleri yaparak, matematikçilerin çalışmalarında izledikleri yolları dikkate alarak ve onların çalışmalarında kullandıkları soyutlamaları yaparak, sürekli bir muhakeme yeteneğine sahip olma durumu olarak tanımlamıştır.

Birçok araştırmacı tüm konu alanlarına genel olarak uygulanabilecek az sayıda düşünme alışkanlığı olduğu konusunda hem fikirdir (Wegerif, 2002). Bu durumda her bir alana uygun düşünme alışkanlıklarının neler olduğunu ortaya koymaya çalışmak kaçınılmazdır. Bu bağlamda Driscoll, DiMatteo, Nikula ve Egan (2007) öğretmenlerin 5.-10. sınıf öğrencilerinin geometrik düşünme becerilerini geliştirebilmeleri için nasıl bir yol izlemeleri gerektiği üzerine yaptıkları çalışmada geometrik düşünme alışkanlıkları kavramını geliştirmiş ve bunları dört grupta sınıflandırmıştır: iliş̧ki kurarak muhakeme etme, geometrik fikirlerin genelleştirilmesi, değişmeyenlerin incelenmesi, keşfetme ve yansıma dengesi kurma. Driscoll ve diğerleri (2007) öğrencilerin ve yetişkinlerin başarılı birer geometrik problem çözücüleri olmaları için çeşitli düşünme yolları tanımlamış ve geometrik düşünme şekillerinin analizlerine yer vermiştir. Söz konusu çalışma sonucunda geometrideki düşünme alışkanlıkların bir çerçevesi çizilmiş ve geometrik düşünmenin geliştirilmesinde bu çerçevenin bir araç olarak kullanılması önerilmiştir. $\mathrm{Bu}$ dört geometrideki düşünme alışkanlığı aşağıda ayrıntılı bir şekilde açıklanmıştır.

İlişki Kurarak Muhakeme Etme: Driscoll ve diğerleri (2007) ilişki kurarak muhakeme etme alışkanlığını, bir geometrik şeklin kendi içindeki ya da geometrik şekillerin aralarındaki ilişkileri (örneğin eşlik, benzerlik, paralellik) inceleme ve bu ilişkileri problemi anlamada veya problemin çözümünde ne şekilde kullanacağına karar verebilme süreci olarak tanımlamaktadır. Birey farklı şekiller arasındaki ilişkilere, bir şekle veya şeklin içindeki alt şekillere odaklandığı 
zaman ilişki kurarak muhakeme etme alışkanlığında, bir takım göstergeler meydana gelmektedir. Bu göstergeler özel muhakeme becerilerini (örneğin, orantısal akı1 yürütme yapma ve simetriden yararlanma) içermektedir.

Geometrik Fikirlerin Genelleştirilmesi: Geometrik fikirlerin genelleştirilmesi alışkanlığı, geometrik kavramların genellikle ve tüm kavramlarıyla olan ilişkileri anlama ve açılamayı isteme olarak tanımlanabilir. Bu alışkanlık, bireyin konuyla ilgili özel durumları göz önünde bulundurması, özel durumlardan ayrıca başka uygun örnekler araması, önceden tanımlanmış durumların özelliklerinin değişmesiyle yeni durumlar üretmeye çalışması, nasıl yapılacağını bilmediği halde başka çözümler de olabileceğini sezmesi, verilen sonsuz bir durumu açıklayabilmek için belirli bir durumdan yola çıkarak çalışması gerektiğinin farkına varması gibi göstergeler içerir (Driscoll ve diğerleri, 2007).

Değişmeyenlerin İncelenmesi: Değişmeyenlerin incelenmesi alışkanlığ ise bir geometrik şeklin yansıma, öteleme, döndürme gibi dönüşümü sonucunda hangi özelliğin değişip hangi özelliğinin aynı kalacağını analiz etme olarak tanımlanmaktadır. Değişmeyenlerin incelenmesi alışkanlığı ise bireyin statik bir durum hakkında dinamik düşünmesi, bir dönüşüm yapıldığında nelerin aynı nelerin farklı kalacağını merak etmesi, arka arkaya yapılan dönüşüm sonuçlarına ve özelliklerine bakması, bir noktanın veya bir şeklin dönüşümünde süreklilik olduğunda sonuçlarını ve iki dönüşüm arasında başka bir dönüşüm daha olacağını tahmin etmesi, gerçekleşen dönüşüm uç noktalarını düşünmesi gibi göstergeler içermektedir (Driscoll ve diğerleri, 2007).

Keşfetme ve Yansıma Dengesi Kurma: Keşfetme ve yansıma dengesi kurma alışkanlığ bir problemin çözümü için farklı yaklaşımlar deneme ve düzenli olarak geri dönerek durum değerlendirmesi yapma süreci olarak tanımlanmıştır. Keşfetme ve yansıma dengesi kurma alışkanlığı ise tahmin ve sezme yoluyla şekil üzerinde çizim, oynama ve/veya keşif yapma, çizim, oynama ve/veya keşif yaparken sürekli durum değerlendirmesi yapma, önceki benzer durumların denemesini yapma, bir durumun, bir koşulun ya da bir geometrik şeklin bazı özelliklerini değiştirme ve değişiklikleri inceleme, ilerlemenin ölçütü olarak belirli aralıklarla büyük resme bakma, çözüme yardımcı olacak ara adımları belirleme, nihai çözümün nasıl olabileceğini açıklama, çözümle ilgili gerekçeli varsayımlar yapma ve gerekçeli varsayımları sinayacak yollar geliştirme göstergelerini kapsamaktadır (Driscoll ve diğerleri, 2007).

İlgili alan yazında öğretmen, öğrenci ve öğretmen adaylarının geometrik düşünme alışkanlıklarını belirleme ve bu alışkanlıkları kazandırma çalışmaları yer almaktadır. Örneğin, Özen (2015) çalışmasında ortaokul matematik öğretmenlerinin ders imecesi sonrasında geometrik düşünme alışkanlıklarında, buna bağlı olarak da geometrik düşünmelerinde gelişme olduğunu, öğretmenlerin bunu öğretim süreçlerine yansıttıklarını ve öğretmenlerin daha çok ilişkilendirme ve genelleme bileşenlerini derslerinde kullandıklarını saptanmıştır. Ortaokul öğretmenleri ile yapılan benzer bir çalışmada ise geometrik düşünme alışkanlıklarını kazandırmaya yönelik etkinliklerle öğretmenlere eğitimler verilmiş, sonra bu öğretmenlerin etkinlikleri sınıflarında uygulamaları istenmiştir; fakat öğrencilerin yapılan etkinlikler sonrasında geometrik düşünme düzeylerinde herhangi bir gelişme olmadığ1 belirlenmiştir (Yıldız, 2018). Öğretmen adayları ile yapılan çalışmalar ise onların geometrik düşünme alışkanlıkları kapsamında eksikliklerinin olduğu ortaya koymaktadır (Bülbül, 2016; Köse ve Tanışl1, 2014). Köse ve Tanışlı'nın (2014) öğretmen adayları ile yapılan çalışmasında, ilişki kurarak muhakeme etme alışkanlığı kapsamında adayların problemlerde yer alan geometrik şekilleri birbirinden bağımsız olarak düşündüğü, geometrik fikirlerin genelleştirilmesi kapsamında adayların özel durumlarda aşırı genellemeye vardıkları, değişmeyenlerin incelenmesi kapsamında adayların çoğunun geometrik şekillerin uygun dönüşümler altında bir noktanın ya da şeklin sürekli hareketini göz önünde bulunduramadığı belirtilmiştir. Sonuç olarak, yapılan çalışmaların genellikle öğretmen, öğrenci ve öğretmen adayları ile yapıldığı ve bunların geometrik düşünme alışkanlıklarında ciddi eksiklikler olduğu vurgulanmıştır. 


\section{Araştırmanın önemi ve araştırma sorusu}

Çalışmalar göstermektedir ki, öğretmenler öğrencileriyle birlikte geometri problemleri üzerinde çalışmalı, onların kendi düşüncelerini dile getirmelerine yardımcı olmalı ve öğrencilerin geometrik düşünme alışkanlıklarını geliştirmek için uygun ortamlar yaratmalıdır. Öğretmenlerin böylesi bir ortamı sağlamaları için öncelikle kendilerinin geometrik zihinsel alışkanlıklara sahip olmaları gerekmektedir (Driscoll ve diğerleri, 2007). Geometrik düşünme alışkanlıklarının öğretim programlarının önemli bir öğesi olduğu düşünüldüğünde (Cuoco ve diğerleri, 2010), öğretmenlere rehberlik eden öğretim programlarının önemi de ön plana çıkmaktadır. Bununla birlikte, öğrencilerin sahip oldukları geometrik düşünme alışkanlıklarının daha sonraki öğrenim hayatlarını etkileyeceği göz önünde bulundurulduğunda, matematik öğretim programlarında geometrik düşünme alışkanlıklarının incelenmesinin bu araştırmanın önemini daha da ortaya koyacağ 1 anlaşılmaktadır. Geometri öğretimi ve öğrenimi için önemli bir kavram olan geometrik düşünme alışkanlıklarının programlara nasıl yansıtıldığını inceleyen bu çalışmanın alana önemli bir katkı sağlayacağı umulmaktadır.

$\mathrm{Bu}$ çalışmanın amacı, Cumhuriyetin ilanından günümüze (1924-2018) ortaokul matematik öğretim programlarında yer alan geometri ve ölçme öğrenme alanındaki kazanımları geometrik düşünme alışkanlıkları bakımından incelemektir. $\mathrm{Bu}$ amaçla, bu öğretim programlarındaki kazanımların geometrik düşünme alışkanlıkları bakımından 6., 7., ve 8. sınıf düzeyinde nasıl bir değişim gösterdiği araştırılmaya çalışılmıştır. Araştırma sorusu şu şekilde oluşturulmuştur: 1924-2018 yılları ortaokul matematik öğretim programları geometri ve ölçme öğrenme alanı kazanımlarındaki geometrik düşünme alışkanlıkları nasıl değişim göstermektedir?

\section{Yöntem}

$\mathrm{Bu}$ araştırmada, Cumhuriyetin ilanından günümüze uygulanan ortaokul matematik öğretim programları taranmış, kazanımlar geometrik düşünme alışkanlıkları bakımından betimlenmiştir. $\mathrm{Bu}$ nedenle, bu çalışmanın modeli tarama modeli olarak tercih edilmiştir. Bu tür araştırmalarda, geçmişte ya da halen var olan bir durum var olduğu şekliyle betimlenmekte, ele alınan olaylar ve durumlar ayrıntılı bir biçimde araştırılmaktadır (Karasar, 2014). Bu bağlamda, 1924, 1930, 1938, 1949, 1951, 1962, 1970, 1988, 1995, 1997, 2002, 2005, 2009, 2013, 2015 ve 2018 tarihli ortaokul matematik öğretim programları bu çalışmanın kapsamını oluşturmaktadır. Bu öğretim programlarının geometri ve ölçme öğrenme alanı kazanımları geometrik düşünme alışkanlıkları bakımından derinlemesine incelenmiştir.

\section{Çalışmada incelenen ortaokul matematik dersi programları}

Çalışma kapsamında incelenen on altı ortaokul matematik dersi öğretim programına Milli Eğitim Bakanlığı Talim ve Terbiye Kurulu Başkanlığı kütüphanesinden ve Milli Eğitim Bakanlığı ağ sayfasından erişilmiştir. Bu kapsamda şu öğretim programlarına ulaşılmıştır: 1924 ve 1930 tarihli Orta Mektep Müfredat Programı, 1938, 1949, 1951, 1962, 1970, 1988 tarihli Ortaokul Programı, 1995 tarihli İlköğretim Okulu II. Kademe programı, 1997 tarihli İlköğretim Program taslağı, 2002 tarihli İlköğretim Okulu Matematik programı, 2005 tarihli İlköğretim Matematik dersi 6-8. Sinıflar Öğretim programı ve kılavuzu (Taslak Basım), 2009 tarihli İlköğretim Matematik dersi 6-8. Sinıflar Öğretim programı ve kılavuzu, 2013 ve 2015 tarihli Ortaokul Matematik dersi 5-8. Sınıflar Öğretim programı ve kılavuzu, 2018 tarihli Matematik Dersi Öğretim Programı (İlkokul ve Ortaokul 1, 2, 3, 4, 5, 6, 7 ve 8. Sinıflar). Türkiye Cumhuriyeti tarihinin ilk matematik öğretim programı olan 1924 programı, Osmanlı Türkçesiyle kaleme alınmış ve 1930 yılına kadar uygulamada kalmıştır (Maarif Vekâleti, 1924). 1930 yılında uygulamaya konan program ise sekiz yıl uygulamada kaldıktan sonra yürürlükten kaldırılmıştır (Maarif Vekâleti, 1930). 1938 yılı programı on bir yıl uygulandıktan sonra yerini 1949 yılı programına bırakmıştır (Maarif Vekâleti, 1938). 1949 öğretim programı ise sonrasında uygulamaya konulan 1951, 1962 ve 1970 yılı programlarında da büyük ölçüde korunmuş ve 1988 yılına kadar kullanılmıştır (Milli Eğitim Bakanlığı [MEB], 1949, 1951, 1962, 1970). 1988 programı yedi yıl uygulamada kalmıştır (MEB, 1988). 1995 yılında yürürlüğe giren öğretim 
programı ise sadece iki yıl yürürlükte kalmış ve geometrik kazanımlar açısından önceki programlarda sağlanan çeşitliliğin gerisinde yer alan bir program olarak tarihe geçmiştir (MEB, 1995). 1997 ve 2002 yılı programları ise aynı içeriğe sahip olup 2005 y1lı programı yürürlüğe girene kadar uygulanmıştır (MEB, 1997, 2002). Bu dönemde MEB'in değişen felsefesi doğrultusunda yeni öğretim programları geliştirme, yenileme ve güncelleme çalışmaları 2005 programını ortaya çıkarmıştır. 2005 matematik öğretim programı ise daha sonra sadeleştirilmiş, 2013-2014 ve 2016-2017 eğitim öğretim yıllarında da matematik öğretim programlarında değişiklikler yapılmıştır.

\section{Veri toplama}

Verilerin toplanması süreci iki adımda gerçekleştirilmiştir. Birinci adımda, çalışmada incelenecek dokümanlara ulaşılmıştır. Bogdan ve Biklen (1992) ve Goetz ve LeCompte'e (1984) göre eğitim ile ilgili çalışmalarda, ders kitapları, program yönergeleri, okul içi ve dışı yazışmalar, öğrenci kayıtları, toplantı tutanakları, öğrenci rehberlik kayıt ve dosyaları, öğrenci ve öğretmen el kitapları, ders ve ünite planları, öğretmen dosyaları, öğrenci portföy dosyaları, eğitim ile ilgili resmi belgeler vb. veri kaynağı olarak kullanılabilmektedir. Bu çerçevede çalışmanın verilerini ortaokul matematik dersi öğretim programları oluşturmuştur.

Veri toplama sürecinin ikinci adımında, her bir öğretim programı araştırmanın amacı doğrultusunda incelenmiştir. 1924 öğretim programında yer alan matematik dersi hedeflerinin Osmanlıca olması nedeniyle öncelikle yeni yazıya çevirisi bu alanda uzman bir akademisyenden yardım alınarak yapılmış ve çalışmada bu çeviri kullanılmıştır. 1930 öğretim programında yer alan geometrik şekillerin Arapça isimleri günümüz Türkçesine çevrilmiştir. Ayrıca günümüzde ortaokul 6., 7. ve 8. sınıf olarak adlandırılan öğretim düzeyi, Cumhuriyet tarihi boyunca ortaokul 1., 2., ve 3. sınıf ya da İlköğretim II. Kademe 1., 2. ve 3. sınıf gibi farklı adlar almıştır. $\mathrm{Bu}$ araştırmada karışıklığa neden olmamak için ortaokul 6., 7. ve 8. sınıf adlandırması tercih edilmiştir. Bununla birlikte, ortaokul düzeyi olarak kabul edilen 5. sınıf önceki yıllarda ilkokul düzeyinde kabul edildiği için bu çalışmaya bu sınıf düzeyi dâhil edilmemiştir.

\section{Verilerin analizi}

Verilerin analizi için nitel analiz tekniklerinden doküman analizi kullanılmıştır. $\mathrm{Bu}$ analiz, araştırmada hedeflenen olgu ya da olgular hakkında bilgi içeren yazılı materyallerin incelemesini kapsamaktadır (Yıldırım ve Şimşek, 2011). Verilerin analizi sürecinde ortaokul matematik öğretim programları içerik analizi yapılarak çözümlenmiştir. Analizlerde, Driscoll ve diğerlerinin (2007) ortaya koyduğu geometrik düşünme alışkanlıkları temel alınmıştır. Bu kapsamda, geometri ve ölçme öğrenme alanındaki kazanımlar ilişki kurarak muhakeme etme, fikirlerin genelleştirilmesi, değişmeyenlerin incelenmesi ve keşfetme ve yansıma dengesi kurma alışkanlıklarına göre kodlanmıştır. Kodlama aşamasında, Tablo 1'de gösterildiği üzere, bu alışkanlıklar için tanımlayıcı kodlar oluşturulmuştur. Bununla birlikte, matematik öğretim programlarındaki her bir kazanım sadece bir alışkanlığa dâhil edilecek şekilde kodlanmıştır. Örneğin, "Çevre uzunluğu ile alan arasındaki ilişkiyi açıklar" (MEB, 2009, s.258) kazanımına dair açıklamada alanı verilen dikdörtgensel bir bölgenin sahip olacağı en küçük ve en büyük çevre uzunluğunun belirlenmesi özelliği uç durumları düşünme gerektirdiğinden değişmeyenlerin incelenmesi olarak kodlanmıştır. "Dairenin ve daire diliminin alanını tahmin eder" (MEB, 2009, s. 260) kazanımına ait açıklamada kâğı̈t üzerine çizilen bir dairenin sekiz eş parçaya bölündükten sonra kesilip oluşan daire dilimlerinden paralelkenar oluşturarak dairenin ve daire dilimlerinin alanını tahmin etmeye yönlendirme yapılmasından dolayı keşfetme ve yansıma dengesi kurma alışkanlığ 1 olarak kodlanmıştır. Kodlama aşamasında, kodların güvenirliğini sağlamak için araştırmacıların her biri bağımsız olarak kodlamalarını gerçekleştirmiştir. İlk kodlamada kodlayıcılar arası tutarlılık \%82 iken yapılan ikili görüşmelerden sonra kodlayıcılar arası tam tutarlılık sağlanmıştır. 
Tablo 1.

Geometrik Düşünme Alıșkanlıklarına Yönelik Tema ve Kodlar

\begin{tabular}{|c|c|}
\hline Temalar & Kodlar \\
\hline İlişki Kurarak Muhakeme Etme & $\begin{array}{l}\text { Tanıma (geometrik şekillerin özelliklerini bilme, farkl } \\
\text { geometrik şekilleri birbirleriyle karşılaştırarak } \\
\text { ilişkilendirme), orantısal akıl yürütme (eşlik ve benzerlik), } \\
\text { simetri kullanma }\end{array}$ \\
\hline Fikirlerin Genelleştirilmesi & $\begin{array}{l}\text { Tüm olası durumları bulma, bilinenden bilinmeyeni } \\
\text { bulma, özel bir durumdan hareket etme ve bunu genele } \\
\text { uyarlama }\end{array}$ \\
\hline Değişmeyenlerin İncelenmesi & $\begin{array}{l}\text { Bazı özellikler değişse bile hep sabit kalan yani } \\
\text { değişmeyen özellikleri fark etme, uç durumları } \\
\text { düşünebilme }\end{array}$ \\
\hline $\begin{array}{l}\text { Keşfetme ve Yansıma Dengesi } \\
\text { Kurma }\end{array}$ & $\begin{array}{l}\text { Kontrollü bir keşif süreci izleme, farklı çözüm stratejileri } \\
\text { geliştirme, problemin çözünün doğruluğu konusunda } \\
\text { tutarlı açklamalar yapabilme }\end{array}$ \\
\hline
\end{tabular}

Matematik öğretim programları incelendiğinde bazı yılların öğretim programlarında kazanımlar değişmemiştir. Kazanımları değişmeden kalan öğretim programları şunlardır: 1949/1951/1962/1970, 1997/2002, 2005/2009, 2013/2015. Bu kapsamda, 1949/1951/1962/1970 öğretim programlarından 1970, 1997/2002 öğretim programlarından 2002, benzer biçimde 2013/2015 öğretim programlarından 2015 öğretim programlarının kazanımları incelenmiş ve bunlar çalışmaya dâhil edilmiştir. Diğer taraftan, 2005/2009 programlarından alan yazında 2005 öğretim programına çok vurgu yapıldı̆̆ için diğerlerinden farklı olarak çalışmaya 2005 öğretim programı alınmıştır. Ayrıca Cumhuriyetten günümüze uygulanan ortaokul matematik öğretim programları incelendiğinde, 2005 yılı öncesi programlarda kazanım kavramının yerine farklı kavramların kullanıldığı görülmüştür. Bu çalışmada karışıklığa neden olmamak için kazanım kavramı tercih edilmiştir.

\section{Bulgular}

Bu bölümünde bulgular 6., 7. ve 8. sinıf seviyesinde sunulmuştur. 6. sinıf matematik öğretim programları geometri ve ölçme öğrenme alanındaki kazanımların geometrik düşünme alışkanlıklarına ilişkin bulguları Tablo 2'de gösterilmiştir.

Tablo 2.

6. Sınıf Matematik Öğretim Programları Geometri ve Ölçme Öğrenme Alanı Kazanımlarının Geometrik Düşünme Alışkanlıkları Frekans ve Yüzdesi

$\begin{array}{llll}\text { İlişki Kurarak } & \text { Geometrik } & \text { Değişmeyenlerin } & \text { Keşfetme ve } \\ \text { Muhakeme Etme } & \text { Fikirlerin } & \text { İncelenmesi } & \text { Yansıma } \\ & \text { Genelleştirilmesi } & & \text { Dengesi } \\ & & & \text { Kurma }\end{array}$

\begin{tabular}{|c|c|c|c|c|}
\hline Yil & $f(\%)$ & $f(\%)$ & $f(\%)$ & $f(\%)$ \\
\hline 1924 & $16(94.12)$ & $1(5.88)$ & & \\
\hline 1930 & 17 (77.27) & $5(22.73)$ & & \\
\hline 1938 & $3(100)$ & & & \\
\hline 1970 & $7(77.78)$ & & $1(11.11)$ & $1(11.11)$ \\
\hline 1988 & $4(57.14)$ & $2(28.57)$ & & $1(14.29)$ \\
\hline 1995 & $10(100)$ & & & \\
\hline 2002 & $62(81.58)$ & $8(10.53)$ & & $6(7.89)$ \\
\hline 2005 & $12(42.86)$ & 3 (10.71) & $2(7.14)$ & $11(39.29)$ \\
\hline 2015 & $9(56.25)$ & 3 (18.75) & $1(6.25)$ & $3(18.75)$ \\
\hline 2018 & $6(46.15)$ & $3(23.08)$ & $1(7.69)$ & $3(23.08)$ \\
\hline
\end{tabular}


Tablo 2'de görüldüğü üzere, 6. sinıf matematik öğretim programlarında yer alan geometri ve ölçme öğrenme alanındaki kazanımlar geometrik düşünme alışkanlıkları bakımından incelendiğinde, 1924-2018 yılları arasındaki kazanımlar en çok ilişki kurarak muhakeme etme alışkanlığını yansıtmaktadır. 1938 ve 1995 programları incelendiğinde ise kazanımlarda sadece ilişki kurarak muhakeme etme alışkanlığ 1 yer almaktadır. Şekil 1, 6.sınıf geometri ve ölçme öğrenme alanındaki kazanımların geometrik düşünme alışkanlıklarına ilişkin yıllara göre dağılımını göstermektedir.

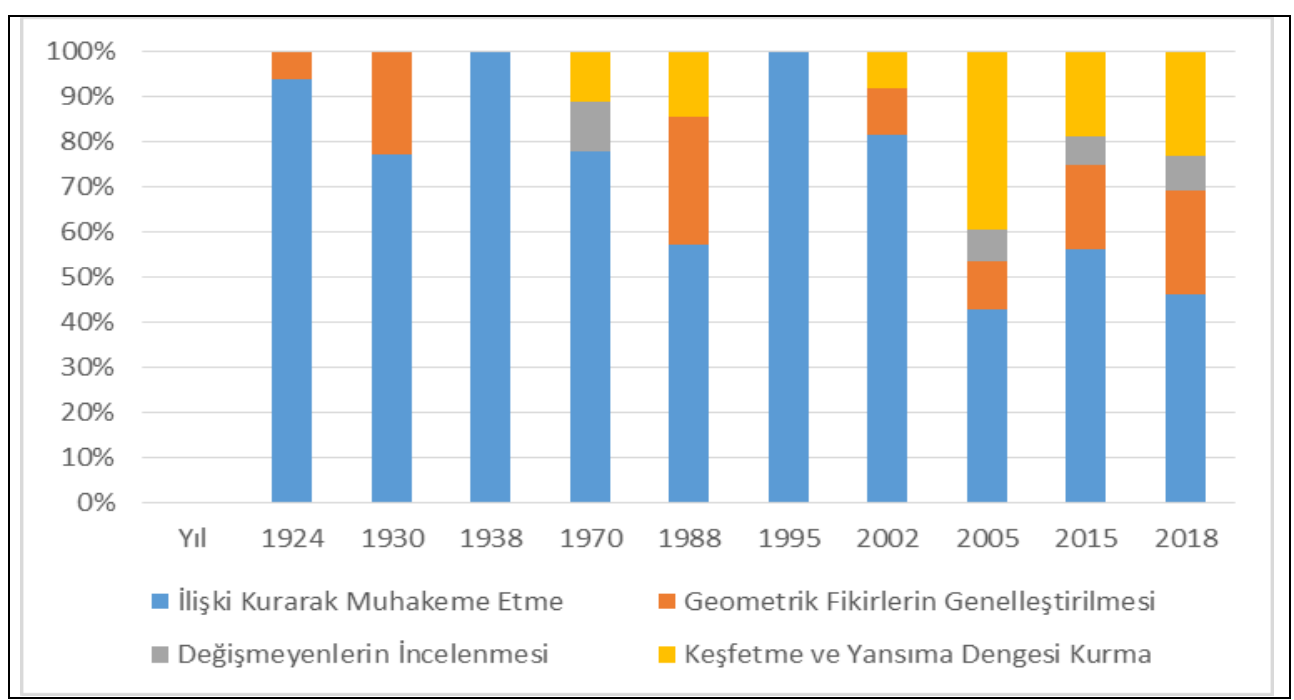

Şekil 1. Ortaokul 6. Sınıf Matematik Öğretim Programı Geometri ve Ölçme Öğrenme Alanındaki Kazanımların Geometrik Düşünme Alışkanlıkları Bakımından Yıllara Göre Dağılımı

Şekil 1'e göre 2002 ve sonrası öğretim programları incelendiğinde kazanımlarda geometrik fikirlerin genelleştirilmesi ve keşfetme ve yansıma dengesini kurma alışkanlıklarının ağırlık kazandığ 1 görülmektedir. Bununla birlikte 2005 ve sonrası öğretim programlarında dört geometrik düşünme alışkanlığını edindirmeye yönelik kazanımlara yer verildiği görülmektedir. 7. sınıf matematik öğretim programları geometri ve ölçme öğrenme alanındaki kazanımların geometrik düşünme alışkanlıklarına ilişkin bulgular Tablo 3’te gösterilmiştir.

Tablo 3

7. Sınıf Matematik Öğretim Programı Geometri ve Ölçme Öğrenme Alanı Kazanımlarının Geometrik Düşünme Alışkanlıkları Frekans ve Yüzdesi

\begin{tabular}{lllll}
\hline & $\begin{array}{l}\text { Illişki Kurarak } \\
\text { Muhakeme Etme }\end{array}$ & $\begin{array}{l}\text { Geometrik } \\
\text { Fikirlerin } \\
\text { Genelleştirilmesi }\end{array}$ & $\begin{array}{l}\text { Değişmeyenlerin } \\
\text { Incelenmesi }\end{array}$ & $\begin{array}{l}\text { Keşfetme ve } \\
\text { Yansıma } \\
\text { Dengesi } \\
\text { Kurma } \\
f(\%)\end{array}$ \\
\hline Y11 & $f(\%)$ & $f(\%)$ & $f(\%)$ & \\
1924 & $15(100)$ & $2(15.38)$ & & \\
1930 & $11(84.62)$ & $1(11.11)$ & & \\
1938 & $8(88.89)$ & $1(20)$ & & \\
1970 & $4(80)$ & $1(8.33)$ & & $4(25)$ \\
1988 & $8(66.67)$ & & $6(13.96)$ & $17(39.53)$ \\
2002 & $21(100)$ & $26(18.84)$ & $7(36.84)$ & $2(10.53)$ \\
2005 & $108(78.26)$ & $4(9.30)$ & $2(16.67)$ & $2(16.67)$ \\
2015 & $8(42.10)$ & $2(10.53)$ & & \\
2018 & $7(58.33)$ & $1(8.33)$ & & \\
\hline
\end{tabular}


Tablo 3'e göre, 7. sınıf matematik öğretim programları geometri ve ölçme öğrenme alanındaki kazanımlar geometrik düşünme alışkanlıkları bakımından dağılımı incelendiğinde 1924-2018 yılları arasında kazanımlarda en çok ilişki kurarak muhakeme etme alışkanlığına yer verildiği gözlenmektedir. 1924 ve 1995 programlarındaki kazanımlarında ise sadece ilişki kurarak muhakeme etme alışkanlığ yer almaktadır. Şekil 2, 7.sınıf geometri ve ölçme öğrenme alanındaki kazanımların geometrik düşünme alışkanlıkları bakımından yıllara göre dağılımını göstermektedir.

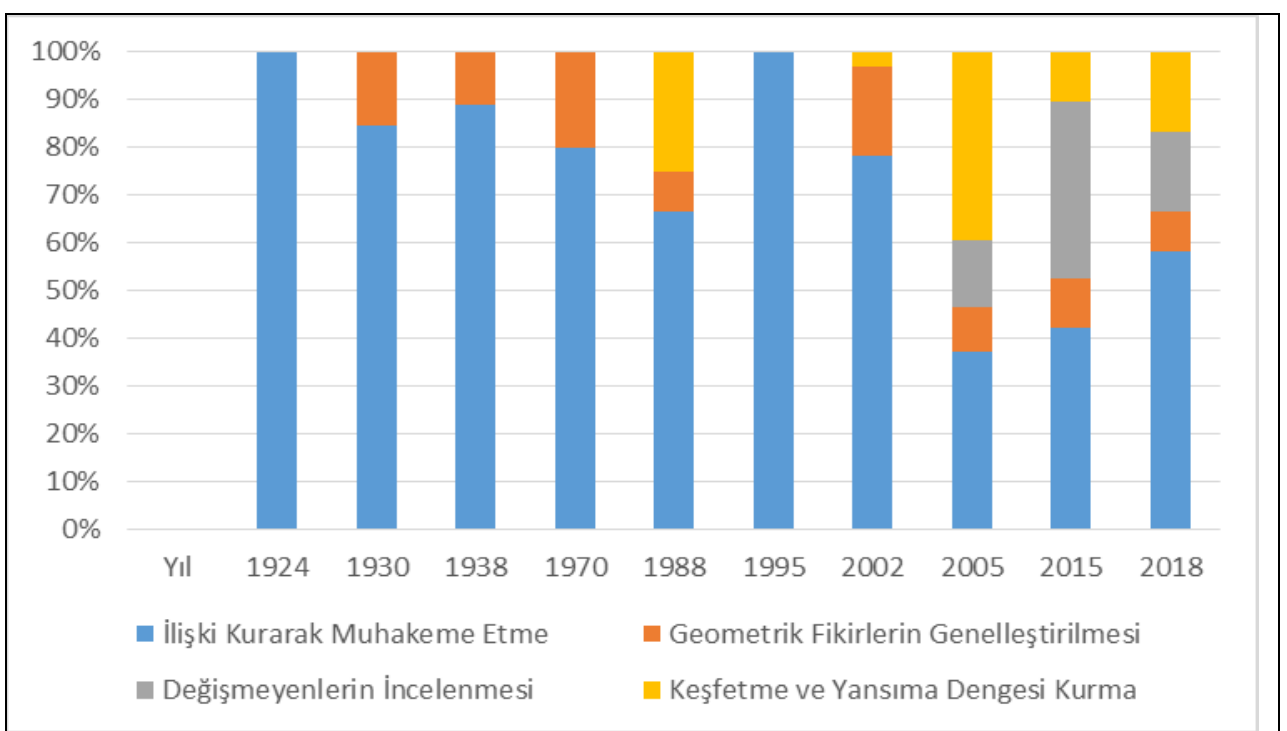

Şekil 2. Ortaokul 7. Sınıf Matematik Öğretim Programı Geometri ve Ölçme Öğrenme Alanındaki Kazanımların Geometrik Düşünme Alışkanlıkları Bakımından Yıllara Göre Dağglımı

Şekil 2'de, 6.sınıf seviyesinde elde edilen bulgulara benzer bir şekilde, 7.sınıf seviyesinde 2005 ve sonrası ögretim programlarındaki kazanımlarda dört geometrik düşünme alışkanlığı ortaya çıkmaktadır. 2015 yılı öğretim programında ise değişmeyenlerin incelenmesi alışkanlığ 1 , ilişki kurarak muhakeme etme alışkanlığ 1 kadar ağırlık kazanmıştır. 8. sınıf matematik öğretim programları geometri ve ölçme öğrenme alanındaki kazanımların geometrik düşünme alışkanlıklarına ilişkin bulgular Tablo 4 'te gösterilmiştir.

Tablo 4

8. Sınıf Matematik Öğretim Programı Geometri ve Ölçme Öğrenme Alanı Kazanımlarının Geometrik Düşünme Alışkanlıkları Frekans ve Yüzdesi

\begin{tabular}{|c|c|c|c|c|}
\hline & $\begin{array}{l}\text { İlisski Kurarak } \\
\text { Muhakeme Etme }\end{array}$ & $\begin{array}{l}\text { Geometrik Fikirlerin } \\
\text { Genelleştirilmesi }\end{array}$ & $\begin{array}{l}\text { Değişmeyenlerin } \\
\text { İncelenmesi }\end{array}$ & $\begin{array}{l}\text { Keşfetme ve } \\
\text { Yansıma Dengesi } \\
\text { Kurma }\end{array}$ \\
\hline Y1l & $f(\%)$ & $f(\%)$ & $f(\%)$ & $f(\%)$ \\
\hline 1924 & $13(100)$ & & & \\
\hline 1930 & $10(90.91)$ & $1(9.09)$ & & \\
\hline 1938 & $8(100)$ & & & \\
\hline 1970 & $4(80)$ & $1(20)$ & & \\
\hline 1988 & $12(92.31)$ & $1(7.69)$ & & \\
\hline 1995 & $17(100)$ & & & \\
\hline 2002 & $60(61.86)$ & $37(38.14)$ & & \\
\hline 2005 & $11(31.43)$ & $7(20)$ & $7(20)$ & $10(28.57)$ \\
\hline 2015 & $5(29.41)$ & $3(17.65)$ & $8(47.06)$ & $1(5.88)$ \\
\hline 2018 & $6(37.5)$ & $2(12.5)$ & $7(43.75)$ & $1(6.25)$ \\
\hline
\end{tabular}


Tablo 4'te, 6. ve 7. sınıf seviyelerinde olduğu gibi 8. sınıf geometri ve ölçme öğrenme alanındaki kazanımlarda ağırlıklı olarak ilişki kurarak muhakeme etme alışkanlığı yer almaktadır. Benzer biçimde, 2005 ve sonrası öğretim programlarında dört geometrik alışkanlığını edindirmeye yönelik kazanımlara yer verildiği anlaşılmaktadır. Şekil 3, 8.sınıf geometri ve ölçme öğrenme alanındaki kazanımların geometrik düşünme alışkanlıklarının yıllara göre dağılımını göstermektedir.

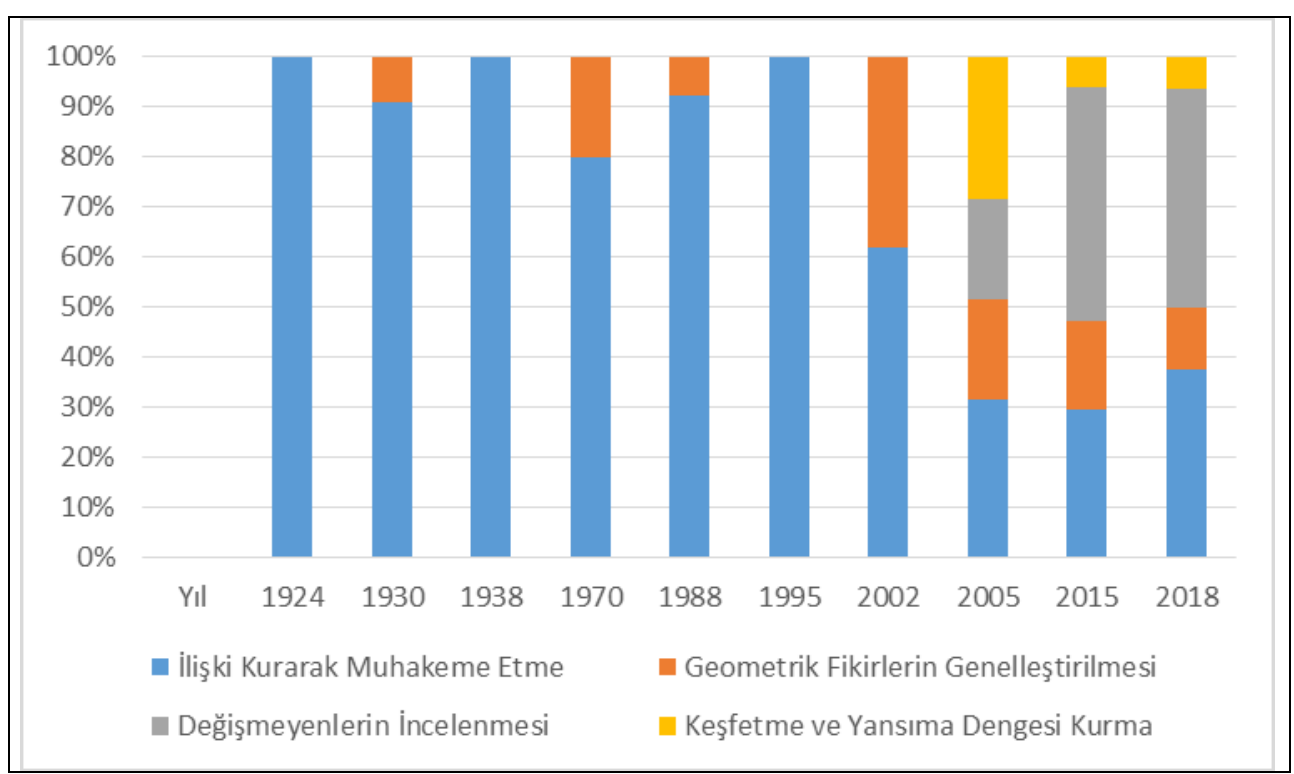

Şekil 3. Ortaokul 8. Sınıf Matematik Öğretim Programı Geometri ve Ölçme Öğrenme Alanındaki Kazanımların Geometrik Düşünme Alışkanlıkları Bakımından Yıllara Göre Dağılımı

Şekil 3'e göre, 1924, 1938 ve 1995 programlarındaki kazanımlarında ise sadece ilişki kurarak muhakeme etme alışkanlığı yer almaktadır. 2005 ve sonrası öğretim programları incelendiğinde değişmeyenlerin incelenmesi alışkanlığı ağırlıklı olarak ortaya çıkmaktadır.

\section{Tartışma / Sonuç ve Öneriler}

$\mathrm{Bu}$ çalışmada, 1924-2018 yılları ortaokul matematik öğretim programları geometri ve ölçme öğrenme alanındaki kazanımlar, geometrik düşünme alışkanlıkları bakımından incelenmiştir. Bulgular göstermektedir ki, bu öğretim programlarında 6., 7. ve 8. sinıf geometri ve ölçme öğrenme alanındaki kazanımlarda ilişki kurarak muhakeme etme alışkanlığı oldukça yüksek bir orana sahiptir. Özellikle, ilişki kurarak muhakeme etme alışkanlığının 1924'ten 2005'e uygulanan ortaokul matematik öğretim programı kazanımlarında hemen hemen tek başına yer alması dikkat çekicidir. Spesifik olarak bu dönemlerdeki programlar incelendiğinde, örneğin 1924, 1962, 1995 programlarındaki geometri kazanımlarında sıklıkla geometrinin temel çizimleriyle ilgili alıştırma ve problemler üzerinde durulmakta, pergel ve cetvel yardımıyla yapılabilen çizimlere yer verilmektedir (Maarif Vekaleti, 1924, 1962, 1995). Bu bakımdan, özelikle 1924-2005 ortaokul matematik öğretim programlarında, çizim etkinlikleri yapmaya yönelik kazanımların olması ilişki kurarak muhakeme etme alışkanlığının desteklenmesi bakımından önemli bir bulgu olarak değerlendirilebilir. Ilişski kurarak muhakeme etme alışkanlığının, geometrik şekillerin kendi içinde ya da diğer geometrik şekiller arasındaki ilişkileri verilen bir problemi anlamada veya problemin çözümünde ne şekilde kullanacağına karar vermede ortaya çıtı̆̆ 1 düşünülürse, bu alışkanlık özellikle ortaokul seviyesindeki öğrenciler için oldukça önemli bir yere sahiptir (Driscoll ve diğerleri, 2007). Bununla beraber, bu alışkanlığın öğretim programlarındaki kazanımlarda yüksek bir oranda yer alması sınıf içindeki uygulamanın nasıl olacağının bir göstergesi olarak nitelendirilebilir. Nitekim matematik 
öğretmen adayları ve öğretmenleri ile yapılan çalışmalarda ise ilişki kurarak muhakeme etme alışkanlığının geometri öğretiminde diğer alışkanlıklara göre daha çok vurgulandığ 1 belirtilmektedir (Bülbül, 2016; Özen, 2015). Sonuç olarak, 1924-2005 yıllarında uygulanan programlarda ortaya çıkan ilişki kurarak muhakeme etme alışkanlığının özellikle ortaokul seviyesindeki öğrencilerin geometrik ilişkiler kurma ve muhakeme etme becerilerinin geliştirilmesinde ve matematik öğretmenlerinin geometri öğretimini şekillendirmesinde oldukça önemli olduğu belirtilebilir.

Çalışmanın önemli bir diğer bulgusu ise 2005 yılından itibaren geometrik fikirlerin genelleştirilmesi, değişmeyenlerin araştırılmast, keşfetme ve yansıma dengesi kurma alışkanlıklarının kazanımlardaki oranının artmasıdır. Driscoll ve diğerleri (2007), dört geometrik düşünme alışkanlığının birbirinden bağımsız olmadığını, bir problem çözücünün bir problemi çözerken birden fazla geometrik alışkanlığını kullanabildiğini ve bu alışkanlıkların geometrik düşünmeye yardımcı olacak uygun soru sorma, problem için ipucu verme gibi öğretim stratejilerine yönlendirdiğini belirtmektedir. Bununla birlikte, bu dört geometrik düşünme alışkanlığı geometrik düşüncenin gelişimi ve geometri öğrenme ile yakından ilişkili olup üst düzey düşünme becerilerinin gelişimine önemli bir katkı sağlamaktadır (Bozkurt ve Koç, 2012; Driscoll ve diğerleri, 2007). Bu bağlamda, 2005 ve sonrası öğretim programlarında geometri ve ölçme öğrenme alanlarına ait kazanımların geometrik düşünme alışkanlıklarını farklı düzeylerde yansıtıyor olması, öğrencinin geometrik düşünmesini üst düzeyde etkileyebilecek niteliktedir. Ayrıca, 2005 ve sonrası matematik öğretim programlarının geometrik düşünme alışkanlıklarını kazandırmayı sağlayacak, iyi yapılandırılmış etkinlik ve problem çözme temelli öğretim yaklaşımlarını benimsediği söylenebilir. Alan yazında yapılan çalışmalar, örneğin Terzi (2010) öğrencilerin düşünme düzeylerinin düşük olduğunu, kısa sürede geometrik düşünme düzeyinin geliştirilemeyeceğini ve lise öncesi sistematik geometri öğretiminin geometrik düşünme düzey gelişimi üzerinde etkili olacağını vurgulamıştır. Benzer biçimde, Erşen (2017) bireylerin geometrik düşünme alışkanlıklarının, öğrenme yaşantılarında karşılaşılan problemlerle şekillendiğini, bu nedenle daha önce karşılaşılmayan problemlerin sınıf ortamında sunularak geliştirilmesi gerektiğini vurgulamıştır. Bu bağlamda, sürece yayılmış keşfetme olanağı sağlayacak etkinlik temelli öğretimin yapılması ve daha önce karşılaşılmayan problemlerin sınıf ortamında sunulması öğrencilerin geometrik düşünme düzeylerinin ve düşünme alışkanlıklarının geliştirmesinde etkili olabileceği söylenebilir.

Düşünme alışkanlıkları çerçevesine hazırlanmış öğretim programı ise öğrencinin matematiksel düşünmesine yardımcı olan en önemli araçlardan biridir (Cuoco ve diğerleri, 2010). Alan yazında da belirtildiği üzere, geometrik düşünme alışkanlıkları ile ilgili yapılan çalışmaların çoğunlukla öğretmen ve öğretmen adayları ile gerçekleştirilmiş olması geometrik düşünme alışkanlıklarının uygulama sürecindeki önemine dikkat çekmektedir. Örneğin, öğretmenlerin geometri ile ilgili aldığ 1 eğitimin yeterli olmadığı, geometrik düşünme düzeylerinin düşük olduğu ve geometrik düşünme düzeyleri ile geçmişteki eğitimleri arasında anlamlı bir ilişki olduğu saptanmıştır (Ahuja, 1996). Benzer şekilde, öğretmen adaylarının sahip oldukları geometrik düşünme düzeylerinin beklenenin altında olduğu vurgulanmıştır (Bal, 2012; Knight, 2006; Köse ve Tanışl1, 2014). Sonuç olarak, programın uygulayıcıları öğretmenlerin geometrik düşünme düzeylerindeki eksiklik ve geometrik düşünme alışkanlıklarındaki yetersizlik bir öğretim programının hedeflerine ulaşamamasının nedenlerinden biri olarak gösterilebilir. Buna ek olarak, geometrik düşünme alışkanlıklarını derslerde gömülü bir şekilde vermek, her bir düşünme alışkanlığının kullanımına yönelik özel öğretim teknikleri oluşturmak, dersin içeriğine yönelik en uygun düşünme alışkanlığını seçmek ve bu gereklilikleri hayata geçirmek öğretmenlere bırakılmıştır (Bülbül, 2016). Sonuç olarak, geometrik düşünme alışkanlıklarının geliştirilmesinde programın olduğu kadar öğretmenlerin de büyük bir rolü olduğu söylenebilir.

\section{Öneriler}

Çalışmanın bulguları program geliştiriciler, öğretmenler, kitap yazarları için bir örnek teşkil edebilecektir. Örneğin, matematik öğretim programları doğrultusunda hazırlanan matematik 
ders kitaplarındaki etkinliklerin ve soruların geometrik düşünme alışkanlıklarını ne oranda kazandırmaya yönelik olduğu incelenebilir. Bununla birlikte, ortaokul öğrencilerinin kazanımlarda yer alan geometrik düşünme alışkanlıklarını ne oranda edindikleri ve bu süreçte karşılaştıkları güçlüklerin neler olduğu incelenebilir. Öğrencilerin geometrik düşünme alışkanlıklarını sürekli canlı tutmak için öğretmenlerin öğrencileri bu alışkanlıkları kullanmaya yöneltmeleri büyük önem taşımaktadır. Bu doğrultuda öğretmenlerin ders işlenişi sırasında ve sınavlarda sordukları sorular incelenerek bu sorunların hangi geometrik düşünme alışkanlığını kullanmaya yönelik olduğu konusunda bir araştırma yapılabilir. Buna ek olarak liselere ve üniversitelere girişte yapılan merkezi sınavlarda geometri alanında adaylara yöneltilen sorular incelenerek bu sorunların hangi geometrik düşünme alışkanlığını kullanmaya yönelik olduğu konusunda da bir çalışma yapılabilir.

\section{Kaynaklar}

Ahuja, O. P. (1996). An investigation in the geometric understanding among elementary preservice teachers. ERA-AARE Conference. Singapore, 29 NovemberErişim adresi: https://www.aare.edu.au/data/publications/1996/ahujo96485.pdf

Bal, A. P. (2012). Öğretmen adaylarının geometrik düşünme düzeyleri ve geometriye yönelik tutumları. Eğitim Bilimleri Araştırmaları Dergisi, 2(1), 22-24.

Balc1, A., Coşkun, E. ve Tamer, M. (2012). Cumhuriyet dönemi Türkçe dersi öğretim programlarının genel amaçları bakımından değerlendirilmesi. Dil ve Edebiyat Eğitimi Dergisi, 1(1), 1-13.

Bogdan, R. C. ve Biklen, S. K. (1992). Qualitative research for education. An introduction to theory and methods. Boston, MA: Allyn \& Bacon.

Bozkurt, A. ve Koç, Y. (2012). İlköğretim matematik öğretmenliği birinci sınıf öğrencilerinin prizma kavramına dair bilgilerinin incelenmesi. Kuram ve Uygulamada Eğitim Bilimleri, 12(4), 2941-2952.

Bülbül, B. Ö. (2016). Matematik ögretmeni adaylarının geometrik düşünme alışkanlıklarını geliştirmeye yönelik tasarlanan ögrenme ortamının değerlendirilmesi (Yayımlanmamış doktora tezi). Karadeniz Teknik Üniversitesi, Eğitim Bilimleri Enstitüsü, Trabzon.

Costa, A. L. ve Kallick, B. (2000). Discovering and exploring habits of mind. Alexandria, VA: Association for Supervision and Currculum Development.

Costa, A. L. ve Kallick, B. (2008). Learning and leading with habits of mind: 16 Essential characteristics for success, Association for Supervision and Curriculum Development 1703 N. Beauregard St. Alexandria, USA.

Cuoco, A., Goldenberg, E. P. ve Mark, J. (2010). Contemporary curriculum issues: Organizing a curriculum around mathematical habits of mind. Mathematics Teacher, 103(9), 682688.

Delil, A. ve Güleş, S. (2007). Yeni ilköğretim 6. sınıf matematik programındaki geometri ve ölçme öğrenme alanlarının yapılandırmacı öğrenme yaklaşımı açısından değerlendirilmesi. Uludă̆ Üniversitesi Eğitim Fakültesi Dergisi, XX(1), 35-48.

Danışman, Ş. ve Karadağ, E. (2015). Öğrenme alanları ve kazanımlar bağlamında 2005 ve 2013 beşinci sınıf matematik öğretim programlarının karşılaştırılması. Turkish Journal of Computer and Mathematics Education, 3(6), 380-398.

Dindyal, J. (2003). Algebraic thinking in geometry at high school level (Unpublished Doctoral Dissertations). Illinois State Universty, Illionois..

Driscoll, M., DiMatteo, R. W., Nikula, J. ve Egan, M. (2007). Fostering geometric thinking. A guide for teachers, grades 5-10. Portsmouth: Heinemann.

Ersoy, E. ve Baser, N. (2013). Matematiksel düşünme ölçeğinin geliştirilmesi. [The development of mathematical thinking scale] Kastamonu Education Journal, 21(4), 1471-1486.

Erşen, Z. B. (2017). Onuncu sınıf fen lisesi öğrencilerinin geometrik düşünme alışkanlıkları ve geometriye yönelik tutumları arasındaki ilişkinin incelenmesi. SDU International Journal of Educational Studies, 4(2), 71-85. 
Girgin, Y. (2011). Cumhuriyet dönemi (1929-1930, 1949,1981) Ortaokul Türkçe öğretimi programlarının içerik, genel ve özel amaçlarıyla karşılaştırmalı gelişim düzeyi. Adnan Menderes Üniversitesi Ĕ̆itim Fakültesi Eğitim Bilimleri Dergisi, 2(1), 11-27.

Goetz, J. ve LeCompte, M. (1984). Data collection strategies. J. Goetz ve M. LeCompte (Yay. haz.), Ethnography and Qualitative Design in Educational Research içinde (ss. 107163). San Diego. CA: Academic Press.

Goldenberg, E. P. (1996). "Habits of mind" as an organizer for the curriculum. Journal of Education, 178(1), 13-34.

Goldenberg, E. P., Cuoco, A. A. ve Mark, J. (1998). A role for geometry in general education. R. Lehrer ve D. Chazan (Yay. haz.) Designing Learning Environments for Developing Understanding of Geometry and Space içinde (ss. 3-44). Mahwah, NJ: Lawrence Erlbaum Associates.

Gökdemir, A. (2013). 1924' den günümüze ilköğretim sosyal bilgiler programlarındaki hukuk konularının incelenmesi (Yayımlanmamış yüksek lisans tezi). Niğde Üniversitesi Eğitim Bilimleri Enstitüsü, Niğde.

Henderson, P. B., Marion, B. Fritz, S. J., Riedesel, C., Hamer, J. ve Scharf, C. (2004). Materials development in support of mathematical thinking. Erişim adresi: http://www.cs.geneseo.edu/ baldwin/math-thinking/iticse2002-paper.pdf

Hew, K. F. ve Cheung, W. S. (2010). Use of three-dimensional (3-D) immersive virtual worlds in K-12 and higher education settings: A review of the research. British Journal of Educational Technology, 41(1), 33-55.

Kablan, Z. (2011). Analysis of elementary mathematics curriculum evaluation studies. Elementary Education Online, 10(3), 1160- 1177.

Kablan, Z., Baran, T. ve Hazer, Ö. (2013). İlköğretim matematik 6-8 öğretim programında hedeflenen davranışların bilişsel süreçler açısından incelenmesi. Ahi Evran Üniversitesi Kırşehir Eğitim Fakültesi Dergisi, 14(1), 347-366.

Karasar, N. (2014). Bilimsel araştırma yöntemi (26.Basım). Ankara: Nobel Yayınları.

Keskin, Y. (2012).Cumhuriyet dönemi ortaokul tarih programlarına yönelik bir analiz: politik ve ideolojik yaklaşımların programlara yansıması: Elektronik Sosyal Bilimler Dergisi, 40(11), 109-128.

Knight, K. C. (2006). An Investigation into the change in the van Hiele levels of understanding geometry of preservice elementary and secondary mathematics teachers (Yayımlanmamış yüksek lisans tezi). The University of Maine, Orono, ABD.

Köse, N. Y. ve Tanışlı, D. (2014). Sınıf öğretmeni adaylarının geometrideki zihinsel alışkanlıkları. Kuram ve Uygulamada Eğitim Bilimleri (KUYEB), 14(3), 1-28. doi: 10.12738/estp.2014.3.1864

Leikin, R. (2007). Habits of mind associated with advanced mathematical thinking and solution spaces of mathematical tasks. Proceedings of the Fifth Conference of the European Society for Research in Mathematics Education. University of Cyprus, Larnaca, Cyprus.

Maarif Vekaleti. (1924). Lise birinci devre müfredat programı. İstanbul: Matbaa-i Âmire.

Maarif Vekaleti. (1930). Orta mektep müfredat programı. İstanbul: Devlet Matbaas1.

Maarif Vekaleti. (1938). Ortaokul programı. İstanbul: Devlet Basımevi.

Mark, J., Cuoco, A., Goldenberg, E. P. ve Sword, S. (2010). Developing mathematical habits of mind. Mathematics Teaching in the Middle School, 15(9), 505-509.

Marzano, R. J., Pickering, D. ve McTighe, J. (1993). Assessing student outcomes: Performance assessment using the dimensions of learning model. Alexandria, VA: Association for Supervision and Curriculum Development.

Milli Eğitim Bakanlığı. (1949). Ortaokul programı. İstanbul: Milli Eğitim Basımevi.

Milli Eğitim Bakanlığı. (1951). Ortaokul programı. İstanbul: Milli Eğitim Basımevi.

Milli Eğitim Bakanlığı. (1962). Ortaokul programı. İstanbul: Milli Eğitim Basımevi.

Milli Eğitim Bakanlığı. (1970). Ortaokul programı. İstanbul: Milli Eğitim Basımevi.

Milli Ĕgitim Bakanlığı. (1995). İlköğretim okulu II. kademe programı. Ankara: Milli Eğitim Basımevi. 
Milli Eğitim Bakanlığı. (1997). İlköğretim matematik program taslă̆ı. Ankara: Milli Ĕgitim Basımevi.

Milli Eğitim Bakanlığı. (2002). İlköğretim okulu matematik programı. İstanbul: Milli Eğitim Basımevi.

Milli Eğitim Bakanlığı. (2009). İlköğretim matematik dersi öğretim programı ve kılavuzu. Ankara: Milli Eğitim Basımevi.

Milli Eğitim, Gençlik ve Spor Bakanlığı. (1988). Ortaokul programı. Ankara: Milli Eğitim Basımevi.

Özen, D. (2015). Ortaokul matematik ögretmenlerinin geometrik düşünmelerinin geliştirilmesi: bir ders imecesi (Yayımlanmamış doktora tezi). Anadolu Üniversitesi Eğitim Bilimleri Enstitüsü, Eskişehir.

Şen, Ö. (2017). Matematik dersi ortaokul öğretim programlarının karşılaştırılması: 2009-20132017. Curr Res Educ, 3(3), 116-128.

Terzi, M. (2010). Van Hiele geometrik düsünme düzeylerine göre tasarlanan öğretim durumlarının ögrencilerin geometrik başart ve geometrik düşünme becerilerine etkisi (Yayımlanmamış doktora tezi). Gazi Üniversitesi. Eğitim Bilimleri Enstitüsü, Ankara.

Trautwein, U., Köller, O., Schmitz, B. ve Baumert, J. (2002). Do homework assignments enhance achievement? A multilevel analysis of 7th grade mathematics. Contemporary Educational Psychology, 27, 26-50.

Uşun, S. (2016). Eğitimde program değerlendirme süreçler-yaklaşımlar ve modeller (2. bask1). Ankara: Anı Yayıncilık.

Van De Walle, J. A., Karp, K. S. ve Bay-Williams, J. M. (2014). Illkokul ve ortaokul matematiği gelişimsel yaklaşımla ögretim. S. Durmuş (Çev.). Ankara: Nobel Akademik Yayıncılık.

Wegerif, R. (2002). Literature review in thinking skills, technology, and learning. Erişim adresi: https://www.nfer.ac.uk/media/1838/futl75.pdf

Yakar, H. (2013). Cumhuriyetten günümüze uygulanmış olan ilköğretim sosyal bilgiler öğretim programlarında seyahatnamelerin incelenmesi (Yayımlanmamış yüksek lisans tezi). İnönü Üniversitesi. Eğitim Bilimleri Enstitüsü, Malatya.

Yıldırım, A. ve Şimşek, H. (2011). Sosyal bilimlerde nitel araştırma yöntemleri (8. baskı). Ankara: Seçkin Yayıncılık.

Yıldız, N. (2018). Ortaokul sınıflarında geometrik düşünmenin geliştirilmesine yönelik bir mesleki gelişim modelinin ögrencilerin van Hiele geometrik düşünme düzeylerine etkisi (Yayımlanmamış doktora tezi). Gaziantep Üniversitesi. Eğitim Bilimleri Enstitüsü, Gaziantep.

\section{Extended Abstract}

\section{Introduction}

The key purpose of mathematics and in particular geometry education programs is to raise individuals who can overcome the problems they face. In order to educate these individuals, it is necessary to shape the teaching programs in accordance with mathematical and geometric habits of minds and to make individuals gain these habits (Cuoco, Goldenberg \& Mark, 2010; Goldenberg, 1996; Mark, Cuoco, Goldenberg \& Sword, 2010). The habits that support the mathematical application and learning of mathematics were considered as equivalent to mathematical power by Goldenberg, Cuoco and Mark (1998), and mathematical power was defined as the best thinking habit of all. Thinking habits that define mathematical power have become more prominent in some special fields of mathematics, for example in algebra and geometry, which have become important fields of study and have gained importance especially during recent years.

Geometric habits of minds are essential for students and adults for a good problem solver in geometry (Driscoll, DiMatteo, Nikula \& Egan, 2007). The geometric habits of minds are an important part of a curriculum, a regulating element of mathematics programs and they can only be taught through teaching programs (Cuoco et al., 2010). In order to raise individuals 
who can overcome the problems they face, it is of great importance to prepare the learning outcomes in the curriculum representing mathematical and geometric thinking habits (Cuoco et al., 2010; Goldenberg, 1996; Mark et al., 2010).

Studies have shown that it is important for teachers to work with their students on geometric problems, help them to express their thoughts and have experiences that will contribute to their students' development of geometric thinking. For teachers to provide such an environment first they must have their own geometric thinking habits (Driscoll et al., 2007). With this aspect, the significance of the teaching programs that guide teachers is very important. While preparing the teaching programs that guide teachers, geometric thinking habits being included is important for students to gain high level thinking skills. Considering the geometric thinking habits of students affect their later on education lives, the analysis of the geometric thinking habits in the curriculums shows the importance of this research once again. It can be said that with this study, which will determine how geometric thinking habits are reflected to the programs, is an important concept for geometry learning and teaching, and that it will create an awareness of the concept of geometric thinking habits in mathematics teachers.

The purpose of the study was to examine the intended learning outcomes in the middle school mathematics curriculum which were applied from 1924 to 2018 with respect to geometric habits of mind. For this purpose, the learning outcomes in these curriculums have been examined in terms of geometric habits of minds for 6th, 7th and 8th grades.

\section{Method}

In this study, middle school mathematics curriculums applied to the present day from the first day of the republic were searched as it was never changed and the intended learning outcomes were described in terms of geometric habits of minds. Descriptive survey model was preferred for this study. In such a study, a past or present situation is accepted as it is, and the events and situations discussed are examined in detail (Karasar, 2014). In this context, the middle school mathematics curriculums which have firstly published in 1924 and 1930, 1938, 1949, 1951, 1962, 1970, 1988, 1995, 1997, 2002, 2005, 2009, 2013, 2015 and 2018 were analyzed in this study.

To analyze the data, document analysis from qualitative analysis techniques was used. This analysis covers the examination of written materials containing information about the targeted facts or facts in the research (Yıldırım \& Şimşek, 2011). Particularly, written documents about middle school mathematics curriculum were resolved by content analysis. The categories of analysis and the codes to represent the identified categories were determined based on the framework of Driscoll et al. (2007).

\section{Result and Discussion}

When the intended learning outcomes in the 6th grade mathematics curriculum were examined in terms of geometric habits of minds, it was observed that the learning outcomes in the curriculums between the years of 1924-2018 mostly represented the habit of reasoning with relationships. When the mathematics curriculums of 1938 and 1995 were analyzed, only the reasoning with relationships was found. When the 2002 and later on mathematics curriculum were examined, it was seen that generalizing geometric ideas and balancing exploration and reflection had gained importance. In addition, it was seen that in 2005 and later on mathematics curriculums, there was a progress in acquiring four geometric habits of minds. When the distribution of the learning outcomes in the field of geometry and learning measurement in terms of geometric habits of minds were examined for 7 th grades, it was observed that there was mostly the reasoning with relationships was found. In the 2015 curriculum, the habit of investigating invariants had gained importance as much as the habit of reasoning with relationships. As in the 6th and 7th grade levels, also in the 8th grade geometry and measurement learning area, it was found mainly the habit of reasoning with relationships. The learning outcomes in the 1924, 1938 and 1995 curriculum, it was only the habit of reasoning 
with relationships. When the curriculums of 2005 and later years were examined, the habit of investigating invariants was predominant.

In this study, the intended learning outcomes in geometry and measurement learning area in terms of geometric habits of minds were examined in the middle school mathematical curriculums between the years of 1924-2018. The findings showed that the 6th, 7th and 8th grades in these programs had a high rate habit of reasoning with relationships in geometry and measurement and learning area. In particular, it was noteworthy that the learning outcomes in the middle school mathematic curriculums applied from 1924 to 2005 represented only the geometric habits of mind of reasoning with relationships. Specifically, when the learning outcomes in the curriculums of 1924, 1962, 1995 were analyzed, often it was focused on the exercises and problems related to the basic drawings of geometry, and frequently the drawings that could be made with the help of compasses and rulers were used (Ministry of Education, 1924, 1962, 1995). In this respect, especially in the 1924-2005 middle school mathematics curriculums, the existence of the learning outcomes including drawing activities could be considered as an important finding in terms of supporting the habit of reasoning with relationships. However, considering that the geometric habits of mind of reasoning with relationships was related to understanding how the connections within the geometric shapes and with the other geometric shapes occur or how to use it when solving problems, this habit played an important role especially for middle school students in building up geometric relations and developing reasoning skills (Driscoll et al., 2007). In this context, it could be said that the habit of reasoning with relationships in the programs applied between 1924-2005 was very important especially for the middle school students. 